\title{
O OUTONO DA ONDA GLOBAL: LIMITES DO ATIVISMO CONTEMPORÂNEO NO ANOITECER DA DEMOCRACIA E DOS DIREITOS SOCIAIS
}

\author{
Francisco Mata Machado Tavares ${ }^{1}$ \\ Matheus Hoffmann Pfrimer²
}

\begin{abstract}
RESUMO: O artigo propõe uma interpretação acerca da paradoxal emergência de governos não democráticos e neoliberais em países onde ocorreram, a partir de 2009, ciclos de confronto político associados a demandas por democratização e justiça econômica. Buscam-se, na subjetividade e na moralidade prevalecentes entre ativistas, elementos que influenciam, ainda que de modo não linear e em conjunto com uma miríade de outros fatores, o desfecho não raramente frustrante das mobilizações. Discute-se, em especial, com base na filosofia política de Jodi Dean, o modo como a subjetividade individual neoliberal e a moralidade da autocompaixão sugerem a presença, no interior das lutas sociais, de aspectos quintessenciais da realidade que se pretendeu transformar.
\end{abstract}

Palavras-chave: Onda Global de Protestos. Declínio democrático. Neoliberalismo. Subjetividade política. Moralidade política.

\section{THE FALL OF THE GLOBAL WAVE: LIMITS OF CONTEMPORARY ACTIVISM AT THE DUSK OF DEMOCRACY AND SOCIAL RIGHTS}

\begin{abstract}
This essay presents a theoretical interpretation for the paradoxical emergence of non-democratic and neoliberal governments in countries where, starting in 2009, contention cycles related to democratization and economic justice grievances have taken place. We look at the prevalent subjectivity and morality among activists, in order to detect factors that - among a myriad of other causes influence (although in a non-linear way) the frustrations related to the outcomes of the mobilizations. We address, especially, anchored on Jodi Dean's political philosophy, how a subjectivity based on the individual and a self-compassion morality suggest the presence, inside the realm of social struggles, of aspects quintessentially bounded to the same reality that the movements aimed to change.
\end{abstract}

Keywords: Global Wave of Protests. Democratic decline. Political subjectivity. Political morality.

\footnotetext{
O presente artigo é resultado de duas pesquisas financiadas pela CAPES (Edital 12/2015 - Memórias Brasileiras/Conflitos Sociais; Transformações do ativismo no Brasil: Junho de 2013 em perspectiva comparada) e CNPq (Edital Universal 01/2016 - Cartografias da Onda Global de Protestos em três atos: Tecnologias, coerção e recursos naturais).

1.Universidade Federal de Goiás - Programa de Pós-graduação em Ciência Política - Goiânia (GO), Brasil. E-mail: franciscotavares@ufg.br 2.Universidade Federal de Goiás - Programa de Pós-graduação em Ciência Política - Goiânia (GO), Brasil. E-mail: matheuspfrimer@ufg.br
} 


\title{
EL OTOÑO DE LA OLA GLOBAL: LÍMITES DEL ACTIVISMO CONTEMPORÁNEO EN EL OCASO DE LA DEMOCRACIA Y LOS DERECHOS SOCIALES
}

\begin{abstract}
RESUMEN: Eso artículo propone, de manera teórica, una interpretación sobre el surgimiento paradójico de gobiernos no democráticos y neoliberales en países donde, desde 2009, ha habido ciclos de confrontación política asociados con demandas de democratización y justicia económica. Se busca en la subjetividad y la moralidad prevalecientes entre los activistas durante la Ola Global de Protestas elementos que influyan, aunque no linealmente y en conjunción con una miríada de otros factores, el resultado a menudo frustrante de las movilizaciones. Se discute, especialmente, con base en la filosofía política de Jodi Dean, la forma en que la subjetividad neoliberal individual y la moralidad de la autocompasión sugieren la presencia, dentro de las luchas sociales, de los aspectos por excelencia de la realidad que pretendía transformar.
\end{abstract}

Palabras-clave: Ola Global de Protestas. Decadencia democrática. Neoliberalismo. Subjetividad política. Moralidad política.

\section{Introdução}

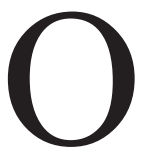

propósito deste artigo é argumentar queaslutas por radicalização democrática, as novasformas de ação coletiva da política confrontacional transgressiva e, em síntese, o momento definido como "Onda Global de Protestos" (FOMINAYA, 2014), "Indignação Global” (BRINGEL, 2015) ou mesmo "Renascimento da História" (BADIOU, 2012) indicou o crepúsculo, antes do alvorecer, de um mundo politicamente mais inclusivo e pautado por formas de participação política excedentes aos estreitos limites do liberalismo político, com suas instituições e formas de legitimação de matriz schumpeteriana.

Aparentemente, assim como a crise de 2008 e as medidas interventivas do Estado sobre a economia, que lhe sucederam imediatamente, não mitigaram a economia neoliberal, também os protestos e as lutas sociais que ganharam o mundo a partir daquele período não sugerem uma realidade de radicalização democrática ou de revitalização das esferas públicas. Ao contrário, este texto parte da premissa de que o mundo contemporâneo é menos democrático e inclusivo do que fora antes dos ciclos de confronto político iniciados em 2009, em meio aos quais associou-se à resistência contra as medidas de contração fiscal supressoras de direitos sociais uma pauta política nitidamente radicaldemocrática (DELLA PORTA, 2015).

Pretende-se identificar-se um par de hipóteses explicativas para tal realidade, pautadas por um olhar ainda incomum na produção bibliográfica destinada a entender as dificuldades globalmente experimentadas pelas democracias. Assim, às leituras institucionalistas (LEVITSKY; ZIBLATT, 2018), econômico-políticas (STREECK, 2014) e culturais (NORRIS; INGLEHARDT, 2019) que têm proliferado sobre a atrofia democrática, experimentada em escala global, ambiciona-se somar uma abordagem centrada na dinâmica dos confrontos políticos imediatamente antecedentes à emergência de governos e práticas de matriz ou tendência autocrática ao redor do mundo.

A aposta metodológica efetiva-se aqui na possibilidade de uma percepção sobre os desdobramentos de conflitos e protestos políticos, e centra-se em sua relação não somente com os 
respectivos contextos sociais, mas, igualmente, com suas próprias escolhas, erros e acertos. Segue-se a concepção teórica segundo a qual a dinâmica das lutas sociais tem a ganhar quando percebida a partir da perspectiva interna aos movimentos, diferentemente do que é mais comum nas abordagens concentradas em encadeamentos entre mecanismos e processos (BARKER; COX, 2002)1.

A pergunta que animou a pesquisa teórica, aqui relatada em forma de ensaio, apresenta-se nos seguintes termos: "Que aspectos próprios à dinâmica das organizações de movimento e aos repertórios adotados em eventos de protestos ocorrentes durante a onda global de protestos iniciada em 2009 podem auxiliar na explicação dos malogros que se sucederam às mobilizações?” O desenvolvimento da argumentação que orbita essa pergunta percorrerá o seguinte itinerário: na segunda seção, a seguir, justifica-se a identificação de uma onda global de protestos a partir de 2009, em oposição tanto a um fenômeno mais denso organizativamente, como o Movimento de Justiça Global, quanto a uma simples coincidência de eventos de protestos avulsos e nada articulados entre si. Adiante, detalham-se os elementos que autorizam a constatação de que, em significativa medida, as lutas sociais em referência neste texto experimentaram reveses e frustrações em seus propósitos. Enfim, a derradeira seção, precedente às considerações finais, expõe, a partir da filosofia política de Jodi Dean, dois elementos próprios às contemporâneas formas de ativismo político, que podem auxiliar na explicação do momento não democrático e infenso aos direitos sociais vivido globalmente após a onda de protestos, nomeadamente o individualismo neoliberal e a cultura de autocompaixão.

A distinção entre fatores internos e externos às organizações de movimento e às interações dos participantes de protestos é aqui exposta com fins estritamente analíticos, nunca ontológicos. Assim, as explicações interpenetram-se e, não raramente, fazem-se indecomponíveis no plano fático. O primado do individualismo neoliberal, por exemplo, associa-se fortemente à lógica social mais ampla do neoliberalismo ou do "capitalismo comunicativo" (DEAN, 2016), assim como a cultura da autocompaixão compreende, mais do que um traço específico à atuação de pessoas que se engajam em protestos ou lutas sociais, um traço peculiar à formação das subjetividades na atualidade, quando o narcísico indivíduo auto-interessado, prevalente desde o liberalismo do século XIX até o final do século XX como epítome da subjetividade ocidental, dá lugar à figura à figura da "sobrevivente", que encontra-se encapsulada em sua individualidade, mas não se beneficia dos proveitos egoístas outrora associados a tal condição (DEAN, 2016).

Uma última ressalva soma-se à ponderação anteriormente relatada: a busca por uma compreensão do contexto de retrocesso democrático a partir das derrotas da Onda Global de Protestos não se pretende rival em relação às demais leituras produzidas sobre o assunto, com foco em aspectos como economia política, instituições eleitorais ou cultura. Espera-se, antes, um aporte argumentativo de ordem estritamente complementar. Não se propõe, tampouco, um encadeamento causal ou linear entre os elementos discutidos e o malogro da Onda Global de Protestos; apenas a exposição teórica da plausibilidade de que aspectos ainda pouco tematizados na literatura científico-social possam ter influência sobre o fenômeno de declínio democrático, hoje tão em voga nas pesquisas de diferentes áreas das humanidades. A contribuição aqui esperada reside em incrementar o debate acadêmico, com uma apresentação pontilhista e desprovida de minudente detalhamento empírico sobre as tendências autocráticas ocorrentes na contemporaneidade. Um olhar sobre os problemas internos aos movimentos pode contribuir para a discussão da hipótese de que o declínio das democracias traduz, entre outros atributos já versados na literatura ${ }^{2}$, uma derrota das ativistas que estiveram nas ruas em várias localidades do mundo desde 2009. 


\section{A Onda Global de Protestos: da Euforia ao Revés}

A história, dada por finda na pax do liberalismo democrático triunfante nos últimos lustros do século XX, parecia renascer ${ }^{3}$. A resposta às medidas impopulares adotadas por governos no contexto da crise econômica eclodida em 2008 entusiasmou a academia e não foram raras as menções jubilosas a um tempo que parecia abrir possibilidades políticas transcendentes aos herméticos canais de vocalização das demandas populares próprios às democracias representativas organizadas com ênfase em um método de competição entre elites acopladas a burocracias partidárias.

Alain Badiou, com a verve poética e criativa que define sua escrita, tão erudita como instigante, viu em processos como os da assim chamada "Primavera Árabe" e, em menor medida, nas lutas da Praça do Sol na Espanha, signos de uma história renascida, em que lutas por "democracia real" constituiriam apenas a face moderada e limitada de um contexto sócio-histórico, no qual, mais do que formas políticas democráticas, a "autoridade da Verdade" e a "Ideia" incondicional da justiça (BADIOU, 2012) estariam a transbordar sobre os escombros de formas sócio-políticas opressoras. Às críticas sobre vazios programáticos nas lutas daquele tempo, Badiou replicava que, antes de um programa, o movimento de reabertura da história celebrava sua própria autoridade ditatorial, entendendo-se ditadura como democracia ad infinutum (BADIOU, 2012). Em tom semelhante, Douzinas (2013) escrevia, em um livro publicado já no ano de 2013, sobre uma "era da resistência" e os promissores prognósticos dos levantes ocorridos na Praça Syntagma, em Atenas, contra as políticas de austeridade, sugerindo que, "se a Grécia é o futuro da Europa, talvez, em outro sentido, a resistência poderia tornar-se o futuro da Europa também"4 (DOUZINAS, 2013, p. 15). Houve, ainda, quem celebrasse, sob léxico huntingtoniano, uma "quarta onda de democratização", centrada no Oriente Médio e no Norte da África e impulsionada por novas tecnologias de informação e comunicação, com ênfase nos telefones celulares (HUSSAIN; HOWARD, 2016). Eram tempos em que se sonhava perigosamente (ZIZEK, 2012) e, inobstante os desdobramentos das lutas observadas desde a Revolução das Panelas na Islândia à Praça Tahir no Egito, da Praça Taksin na Turquia ao Zuccotti nos Estados Unidos, da avenida Paulista no Brasil à Porta do Sol na Espanha, notava-se, com plena nitidez, uma "abertura radical" do futuro (ZIZEK, 2012).

De maneira analiticamente mais centrada, a literatura especificamente versada em confronto político e movimentos sociais percebeu um nexo entre a sucessão dos protestos ocorridos entre 2009 e 2013 em diferentes países. Neste artigo, incorpora-se a caracterização proposta por Fominaya (2014), para a qual teria ocorrido uma "Onda Global de Protestos".

A autora define uma "onda de protestos" como i) temporalmente circunscrita; ii) reativa, até certo ponto, a um contexto econômico-político comum; e iii) com níveis significativos de difusão transnacional entre os movimentos. Diferencia-se, assim, de um "movimento global", a exemplo do "Movimento de Justiça Global”, conhecido pelos protestos de Seattle e Gênova ou pelo Fórum Social Mundial, no início dos anos 2000. Um movimento encerra um grau de conexão entre atores e práticas sociais, que aponta para "transformar o mundo como um todo, antes de partes dele” (FOMINAYA, 2014, p. 183). Na Onda Global de Protestos, ações concentradas em temas locais (p. ex., derrubada de Mubarak, no Egito; combate às políticas determinadas pela “Troika”, na Grécia; preservação de um parque público, na Turquia) influenciam-se mutuamente, permitem aprendizados recíprocos e se valem de repertórios, formas organizativas, horizontes societais e manifestações de subjetividades muito semelhantes. Especificamente, os seguintes atributos comporiam o mosaico da onda global: i) circulação global de informações, táticas, recursos, ideias e pessoas por meio do deslocamento físico de ativistas e de tecnologias de comunicação; ii) identidade coletiva compartilhada, observada em referências cruzadas entre protestos ocorrentes em diferentes localidades; iii) a autonomia, assim entendida como crítica às formas de organização coletiva já existentes, em especial os partidos políticos; iv) o uso disseminado da 
tática de ocupações, segundo a qual lógicas de faça-você-mesmo e de reinvenção de logradouros públicos ganham destaque; v) ações prefigurativas, em que práticas deliberativas e solidárias sugerem a antevisão do mundo que se pretende erigir; e iv) um enquadramento da realidade social comum, a associar a economia política neoliberal à insuficiência da democracia representativa, de modo a se exigir, em linhas gerais, radicalização democrática acoplada à produção de políticas para a inclusão e redistribuição socioeconômica (FOMINAYA, 2014).

São especialmente relevantes para o argumento teórico que este artigo pretende expor a constatação de que ondas de protesto são limitadas no tempo e de que a onda global iniciada com a Revolução das Panelas na Islândia, em 2009, apresenta um traço comum, referente aos anseios por democratização (oscilantes desde o acesso a eleições livres até a radicalização democrática) e ao rechaço às políticas econômicas e sociais de inspiração neoliberal. Quanto à delimitação temporal, tudo isso é predicado relevante para afastar o entendimento de que a Onda Global de Protestos ainda estaria em curso, e de que eventos como as lutas de Hong Kong, no ano de 2019, ou as candidaturas socialistas do Partido Democrata ao Parlamento dos Estados Unidos, em 2018, seriam parte desse fenômeno. É mais preciso delimitar o fim do período em questão com o desaparecimento de protestos que reunissem os atributos i a vi anteriormente mencionados, o que, destarte, ainda que comporte variações, nunca antecede a Islândia de 2009, tampouco ultrapassa o Nuit Debout francês, em março de 2016. Em síntese: há certo distanciamento temporal, apto a permitir balanços e generalizações, ainda que preliminares e pontilhistas, sobre aquele contexto.

É igualmente importante destacar o enquadramento comum dos protestos no que diz respeito à demanda por mais democracia (ou, em alguns casos, simplesmente por alguma democracia) imbricada com o rechaço às políticas neoliberais ${ }^{5}$. Esse atributo, detectado por Fominaya, permite um balanço relativamente tangível dos protestos. Caso os países onde esses ocorreram vivam sob cenários politicamente menos democráticos e economicamente menos inclusivos do que se dava quando ruas e praças foram ocupadas, tem-se um forte signo de que, de fato, a Onda Global de Protestos não apenas está encerrada como (inobstante o aprendizado, os símbolos, a formação de uma geração de ativistas, a emersão de repertórios, a crítica às formas burocratizadas da esquerda política, o uso inovador das tecnologias comunicacionais e tantas contribuições ou conquistas de ímpar relevância) frustrou-se e encontrou derrotas em seus mais nítidos escopos.

A subseção seguinte pretende escrutinar, a partir de casos específicos, o malogro das mobilizações globais entre 2009 e 2016 no que diz respeito à democracia e à inclusão socioeconômica, em oposição às convenções neoliberais.

A perspectiva adotada para cumprir-se esse propósito procura ir além das leituras que, concentradas estritamente nas práticas ocorrentes em praças e ruas ocupadas, propõem que o principal legado dos protestos seria a invenção de novas formas de democracia participativa (FERNANDEZ-SAVÁTER et al., 2017). Por outro lado, não se encampa a tese da redução dos impactos e das práticas políticas posteriores aos protestos a libelos abstratos e polissêmicos, como "populismo", a equiparem desde a Aurora Dourada grega ao Podemos espanhol como manifestações de "um sentimento de antipolítica que pode de fato ameaçar a qualidade da democracia”"6 (O'BRIEN, 2015, p. 344). Tais leituras tendem a propor a democracia liberal como uma normalidade, fora da qual toda forma política seria igualada na condição de risco à democracia.

Opta-se, assim, pela perspectiva que reconhece a complexidade dos ciclos de protestos da segunda década do século XXI, admite os múltiplos vetores a influenciarem os respectivos resultados e entende que, se é verdade que a violência disseminada, a polarização, a radicalização e o fortalecimento de regimes conservadores definem a cena atual, também é certo que os movimentos não perderam a sua relevância, mas é o caso de compreendê-los "a partir de outros parâmetros, ampliando-se nossas pesquisas" 
(BRINGEL; PLEYERS, 2017, p. 24). Incorpora-se, portanto, a tese de que o tempo atual "não implica simplesmente idealizar os movimentos, senão estar disposto a ativar a escuta e o diálogo crítico"8 (BRINGEL; PLEYERS, 2017, p. 22).

\section{Depois do Sonho: Tendências Autocráticas e Neoliberais Após a Onda Global de Protestos}

O quadro europeu posterior à Primavera dos Povos, em 1848, pode ser entendido, em meio às complexidades e ambivalências das lutas por inclusão política e redistribuição econômica que agitaram o Velho Mundo, como menos despótico e excludente. O cenário estadunidense quanto à liberdade de expressão, à igualdade racial e aos direitos civis, nos anos 1960, é, igualmente, mais alvissareiro após os protestos de jovens, veteranos de guerra e moradores de guetos periféricos, do que fora nos tempos do macarthismo. O sistema de Ensino Superior argentino fez-se mais inclusivo e democrático após as lutas estudantis levadas a cabo em Córdoba no ano de 1918. Nesse primeiro balanço da Onda Global de Protestos, ainda sujeito às lutas e confrontações do porvir, semelhante cartão de visitas não pode ser apresentado. A seguir, expõem-se exemplos, não sistemáticos ou exaustivos, que sugerem a plausibilidade do argumento de que retrocessos democráticos e econômico-redistributivos são traço muito frequente da realidade atravessada por inúmeros países onde ocorreram ciclos de confronto político no contexto da Onda Global de Protestos. A identificação de frustrações nos protestos será, aqui, efetivada com base nos seguintes elementos: em primeiro lugar, a crise de legitimidade política e o desgaste das instituições democráticas; e, em segundo, a detração econômica e o enfraquecimento dos pilares distributivos.

Primeiramente, quanto à Islândia, observa-se uma escalada da popularidade dos partidos ligados à direita mais conservadora e propensa à adoção das medidas de austeridade. As eleições de 2013 representaram um turning point em relação aos mecanismos iniciados com os protestos dos Saucepans. Ao longo dos últimos anos, alvo dos protestos de 2009, os tradicionais partidos de direita vêm ganhando cada vez mais apelo, com uma roupagem ultraconservadora e populista (BERGMAN, 2015). Fundamentalmente, prevalecem os partidos Progressista (Framsóknarfokkurinn) e Independência (Sjálfstoðisfokkurinn), a partir de um discurso populista e nacionalista (BERGMAN, 2015). Atrelado à volta dos partidos conservadores ao poder está um declínio da percepção da transparência pública. Segundo os dados da ONG Transparência Internacional, nos últimos dez anos a percepção da transparência declinou em quase 10 pontos percentuais (TRANSPARENCY INTERNATIONAL, 2018).

Na realidade espanhola, o crescimento eleitoral da esquerda, que se associa mais ostensivamente à Onda Global de Protestos, representada pelo Podemos, parece ter chegado ao seu limite, caindo de 65 parlamentares, em 2015, para 48, em 2016, e, já em 2019, 30. A um só tempo, uma força de extrema direita, Vox, experimenta apoio e votações sempre ascendentes - saindo de 47.182 votos, nas eleições gerais de 2016, para 2.664.325 nas de 2019 (em que pese ainda não se apontar como capaz de compor um governo, seja pela dificuldade de somar-se a coalizões, seja por obter, até o presente, dimensão eleitoral inferior à de agremiações como as tradicionais PP e PSOE ou as emergentes Ciudadanos e Podemos). O fato de um país com um passado recente totalitário e uma transição democrática insuficiente (MONEDERO, 2013) vivenciar a emergência de um partido de extrema direita com 24 assentos no Parlamento enquanto a esquerda mais radical parece estagnar-se é, quando menos, signo de que os cantos da Puerta de Sol já não reverberam com a mesma força de outrora. A economia, por 
seu turno, apesar de experimentar recuperação, não superou os tempos de austeridade. Opostamente, os gastos sociais do governo se encontram em queda, oscilando de 17,6\% do PIB em 2014, para 17,1\% em 2015, 16,9\% em 2016, 16,4\%, em 2017, e, enfim, 16,2\%, em 2018 (DE LA PEÑA, 2018).

Nos Estados Unidos, é possível atribuir-se aos ecos dos movimentos Occupy fenômenos como a organização da luta pela igualdade racial e contra o encarceramento seletivo da população afrodescendente, como se vê no emergente movimento Black Lives Matter; uma autêntica primavera feminista, que segue da reconfiguração do espaço privado até movimentos como o Me Too; ou um escoamento das lutas redistributivas e por inclusão política para o âmbito eleitoral, como se dá no crescimento de candidaturas identificadas com o DSA (Democrat Socialists of America), elegendo, por exemplo, para uma cadeira no Parlamento, lideranças como Alexandria Ocasio-Cortez, mulher, jovem, trabalhadora e de origem hispânica, que chegou à institucionalidade política contra as estruturas oligárquicas do seu partido e da política estadunidense em geral. Sabe-se, contudo, que essa é apenas uma faceta ainda não hegemônica da política naquele país. É suficiente dizer que o Presidente dos EUA é Donald Trump, líder xenófobo, racista, misógino, nada respeitoso com os canais democráticos de legitimação e contenção do poder e ao redor de quem grupos organizados identificados sob o nome Alt-Right trazem à cena política da maior força imperialista global tendências autocráticas. No plano econômico, igualmente, o crescimento dos níveis de emprego e uma retomada tímida da atividade econômica não elidem o fato de que o governo rege-se por reformas tributárias regressivas e aversão a medidas regulatórias sobre temas como trabalho (e a luta por 15 dólares de pagamento por hora), meio ambiente (e a luta pelo Green New Deal) e saúde (e a luta por serviço público de saúde universal). Em suma, os EUA, após a Onda Global de Protestos, são governados por um presidente que, não apenas no plano retórico, mas em políticas concretas oscilantes, desde as exonerações fiscais ao grande capital até o recrudescimento repressivo contra migrantes que não possuem documentos, opera de modo antagonicamente oposto ao que desejam as prefigurações do Zucotti Park.

No Brasil, o presidente eleito em 2018 engaja-se em uma luta ideológica e civilizacional contra os paradigmas já estabelecidos do respeito aos direitos humanos e à democracia, enquanto obtém adesão junto ao renovado parlamento para a aprovação de medidas econômicas neoliberais, como a aprovação de uma reforma do sistema público de previdência social que reduz direitos da população mais vulnerável (ARRAIS; VIANA, 2019). O desemprego alcança o nível de quase 13 milhões de indivíduos. Ademais, a transparência na gestão pública vem sendo atacada.

Quanto à Turquia, em um primeiro momento, os protestos tiveram repercussão forte entre insatisfeitos com as políticas de austeridade implementadas pelo governo do AKP, partido fundado pelo presidente Recep Tayyip Erdoğan. Em um momento inicial, logo após os protestos em 2013, o movimento de descontentamento se articulou em torno do HDP (Partido Democrático dos Povos) e alcançou certo sucesso nas eleições de 2015, quando conquistou quase $13 \%$ do eleitorado turco. Embora sua representatividade não tenha sido suficiente para derrotar o partido do presidente, esse resultado expressou o descontentamento popular diante do recrudescimento do governo com relação aos protestos. Em virtude da perda de legitimidade e de apoio das urnas nas eleições de 2015, o presidente Erdoğan passa a adotar medidas cada vez mais drásticas, ao fazer uso da repressão como meio para a dissolução das demandas sociais. Ainda em 2016, há uma suposta tentativa de golpe de estado perpetrada por parte das forças armadas por ordem Fethullah Gülen, líder opositor. Segundo a opinião pública internacional e, especialmente, a oposição turca, o golpe seria a justificativa ideal para que o regime e a repressão se instalassem na Turquia (SMITH, 2016). A contrarreação ao golpe foi intensa e o presidente Erdoğan concedeu imunidade às Forças Armadas para coagir qualquer 
forma de dissidência. Ademais, vários professores, juízes e militares foram detidos ou suspensos após a incidente. Alguns acreditavam que os movimentos de Gezi não teriam repercussões apenas pontuais, uma vez que os resultados das eleições de 2015 representavam transformação política (TÜRKMEN, 2017). Atrelado à crise política está o declínio da performance econômica: o desemprego já atingia $14 \%$ da população economicamente ativa em 2019.

O caso da Síria apresenta-se como uma das mais drásticas contrarreações a ciclos de protestos dos últimos tempos. A sobreposição da política confrontacional aos processos da política internacional desencadeou uma guerra civil. Para o projeto de banco de dados de conflito da Universidade de Upsalla, os protestos na Síria se transmutaram em conflito irregular extraterritorial; ou seja, os confrontos armados já não se dão apenas dentro das fronteiras territoriais (UCDP, 2015). Naturalmente, o conflito não pode mais se traduzir por uma questão de ordem interna, fundamentalmente, devido à ingerência da politica externa de diversos estados e de interesses tão dispares quanto de Rússia, EUA e China no Oriente Médio. Essencialmente, a Síria, desde os anos 1960, já se caracterizava como regime autoritário. Contudo, o recrudescimento do regime, após a ascensão de Bashar Al-Assad, traduz-se como um dos marcos fundantes da conjuntura para a ascensão da "Primavera Síria". Naquele momento, os feitos das medidas de austeridade impostas pelo regime de Al-Assad já se manifestavam na estrutura social. Claramente, ao aprofundamento das clivagens se sobrepuseram questões da secular cisão entre sunitas e xiitas. A escalada do conflito representou o desfalecimento de boa parte das instituições do Estado. O que se encontra é um conjunto de agrupamentos humanos sob a égide de grupos políticos que procuram viabilizar algum tipo de ordem, fazendo menção a conceito de volta à idade média de Minc (1993). Não há, de fato, nem sequer a aplicação de uma forma de soberania relativa. Acreditou-se que o regime de Assad seria destronado. No entanto, a atuação russa no conflito permitiu que as forças leais ao regime lograssem não apenas se igualar diante da forças rebeldes, mas inclusive derrotar o movimento fundamentalista islâmico do Estado Islâmico e Levante. Desta feita, os protestos na Síria desencadearam, em certa parte, o fortalecimento internacional do apoio ao regime de Al-Assad e o recrudescimento militar diante dos grupos insurgentes.

No Egito, enfim, o malogro dos protestos que ocuparam a praça Tahir se plasma nos acontecimentos decorridos a posteriori da saída do presidente Hosni Mubarak. Logo após a realização das eleições e sufragado o representante da Irmandade Muçulmana, Mohamed Morsi, o Egito enfrenta um período de forte instabilidade política e econômica. O campo de ação coletiva dos protestos durante o governo Morsi acaba sendo apropriado pelos setores favoráveis às medidas de austeridade e a uma pretensa "modernização" da economia egípcia. O discurso da necessidade de realizar uma nova reforma constitucional, a fim de impedir alegada implantação do regularismo islâmico da Irmandade Muçulmana simbolizada por Morsi, é o ponto fulcral da contenda. Embora uma parte das manifestações ainda seja favorável a Morsi, os setores ligados ao capital internacional acabam tendo seus interesses contemplados e ele deixa o poder. A deposição por meio das armas acaba acontecendo quando o chefe das Forças Armadas é instado por setores da sociedade. O malogro dos protestos no Egito é, assim, expresso essencialmente pelos baixos níveis de liberdade de imprensa e expressão política. O país não conseguiu lograr a passagem para uma democracia, ainda que imperfeita.

Essa tendência ao fechamento de regimes e ao escasseamento dos direitos sociais indica reveses nas pretensões levadas às praças e ruas durante a Onda Global de Protestos. O fenômeno é multifatorial, complexo e, certamente, sujeito às reversões que a história, aberta e sempre em curso, pode engendrar. O que se pretende, aqui, é explorar apenas um dos elementos que, em complemento a inúmeros outros, pode ajudar na explicação desse quadro. Trata-se de uma leitura interna aos movimentos, com ênfase 
nas formas de subjetividade e na moralidade que, frequentemente, prevalecem na cultura ativista da contemporaneidade. Esse é o objeto da próxima seção.

\section{O que Deu Errado? Hipóteses Para o Malogro da Onda Global de Protestos}

Como a seção antecedente indicou, os países onde ocorreram protestos de fôlego democratizante e opostos ao neoliberalismo entre 2009 e 2016 não se encontram, em geral, sob condições favoráveis em relação a essas dimensões. É certo que, sob um olhar condescendente, pode-se escavar os escombros das democracias em queda e das políticas distributivas minguantes e produzir-se etnografias, prosopografias, histórias de vida e análises de interações, em redes ou grupos focais, que permitam melhor entendimento sobre personalidades empoderadas, gestadas em meio às interações no Zuccotti Park; veganos desafiantes de uma cultura alimentar ofensiva ao clima e à paz, que se encontraram e pela primeira vez despertaram-se para o tema na Porta do Sol; grupos de ajuda mútua que se consolam e acumulam forças para enfrentarem o cenário autocrático do Egito, compostos por estudantes que se viram pela primeira vez na praça Tahir; disseminação de técnicas de segurança no uso dos equipamentos e softwares da web 2.0, que contrabalançam a governamentalidade algorítmica e a vigilância em massa crescentes em escala global; ou organizações de ânimo eleitoral, como os Socialistas Democratas dos EUA e o Podemos da Espanha, os quais revigoram a democracia representativa, para além das lógicas bipartidárias e da marcha ao centro vivenciada na virada do século XX para o século XXI. Certamente, todos esses aspectos, aos quais pode somar-se uma miríade de outros, apontam para desdobramentos socialmente complexos, politicamente emancipatórios e culturalmente transformadores, que permitem a detecção, nas práticas sociais do porvir, de uma longeva reverberação da indignação, das práticas prefigurativas, dos encontros entre insurgentes e dos anseios por mudanças radicais gestados durante a onda global de protestos.

Nada disso, todavia, afasta o quadro exposto na seção anterior. Esse, igualmente, exige explicações empíricas e interpretações teóricas. Adiante, ofertam-se hipóteses para futuras construções mais robustas quanto a essas últimas. Em especial, discutem-se dois elementos frequentes no universo ativista da Onda Global de Protestos: individualismo neoliberal e autocompaixão.

\section{O Duplo Veneno da Política Radical Contemporânea: Individualismo Neoliberal e Autocompaixão}

A busca por um marco zero nas lutas radicais igualitaristas da modernidade é vã e, frequentemente, desnecessária. Sob o prisma da preservação de um espaço econômico privado alheio à intervenção do poder soberano, as resistências francesas às aides, ainda na Idade Média, seriam um registro pertinente (ELIAS, 2011). Já sob a perspectiva do desafio à arrogância etnocêntrica europeia, as lutas haitianas lideradas por Toussaint Louverture parecem dizer mais do que, por exemplo, a independência das Treze Colônias da América do Norte. Essa, por sua vez, define-se como nascedouro para tipos de constitucionalismo e federalismo ainda hoje prevalecentes. Quando o foco, porém, recai sobre a questão da igualdade jurídica e política como direito inalienável de cada indivíduo, não há dúvidas de que a Guerra Civil Inglesa no século XVII pode ser identificada como gênese de conflitos, debates e clivagens na filosofia política, que reverberam até a atualidade. 
Sabe-se que a lógica de Hobbes aceitou as premissas igualitárias dos Levellers e Diggers, reconhecendo, assim, as bases antropofilosóficas do mais radical, insurgente e disruptivo ideário, presente nas lutas enredadas em querelas religiosas e econômicas e travadas entre classes proprietárias, representadas no Parlamento (autoridade real que pretendia impor à Inglaterra padrões despóticos de inspiração francesa), e uma multidão alheia ao Parlamento e às próprias fronteiras físicas de Westminster, a demandar igualdade política, jurídica e econômica. Hobbes conferiu ao ideário radical dos Levellers consequências despóticas (WOOD, 2012). Ao aceitar a igualdade e a liberdade inerentes e naturais em cada indivíduo, Hobbes concluiu que ninguém estaria seguro, uma vez que seria lícito a toda e qualquer pessoa infligir dano, ameaça ou medo ao seu semelhante, diante da igual (e irrefreável) liberdade de agir naturalmente conferida a pessoas contempladas com idêntica infinitude em sua capacidade de conduzir-se conforme o próprio alvedrio. Dessa aporia, a única saída possível para a segurança - e preservação física, em última instância - dos indivíduos residiria na renúncia à liberdade, em favor de uma plenipotenciária autoridade. A combinação entre igualitarismo, liberdade e política radical precisou experimentar uma longa trajetória em solo continental, percorrendo caminhos de Rousseau a Kant, de Ficthe a Hegel e desse a Marx, sob a premissa de que a humanidade se realiza no plural (CHITTY, 1998). Foi assim que a política radical emancipacionista pôde despedir-se do solipsismo e de suas aporias em relação à igualdade e à liberdade, para encontrar-se em subjetividades coletivas como povo ou classe.

Os protestos da onda global contemporânea parecem, todavia, reverberar o momento da Guerra Civil Inglesa no modo como lidam com as subjetividades políticas. Bringel (2015) constata que ressai dessas formas de ativismo "um anseio por horizontalidade, a negação da representação e a rejeição da liderança formal”" . (BRINGEL, 2015, p. 135). Remanescem, portanto, indivíduos justapostos na praça, como arremata o autor em questão: "a ação coletiva [também] sofreu uma mudança: há um protagonismo maior dos indivíduos e das praças públicas” ${ }^{10}$ (BRINGEL, 2015, p. 135). Não é de se estranhar, assim, que candidatos a Leviatã, como Erdoğan, Trump ou os militares egípcios, ressaiam das lutas igualitaristas do tempo presente.

A filósofa marxista e lacaniana Jodi Dean tem se dedicado à compreensão e à crítica do tipo de individualismo reinante na sociedade contemporânea. Em particular, a autora aponta os problemas decorrentes da incorporação, pelo campo da esquerda política, da admissão dos indivíduos como loci da liberdade, da responsabilidade e da ação no espaço público. A redução do político ao pessoal torna as coletividades oprimidas ou exploradas incapazes de fazer frente às formas de dominação sob as quais se encontram. Ao acreditar que uma simples reposição do individualismo consumista pela individualidade cidadã seria suficiente para fazer frente ao mundo neoliberal, tal como se dera no debate da esquerda inglesa, nos anos 1980, no periódico Marxism Today, as lutas contestatórias e igualitaristas aprisionam-se em um terreno no qual desaparecem grupos capazes de vencer seus adversários, para que fiquem, à moda liberal, pessoas cuja resistência ou enfrentamento explica-se e processa-se segundo a lógica do esforço, da responsabilidade e das consequências estritamente individuais (DEAN, 2016).

A luta contra o neoliberalismo e pela democratização incorre em incontornável aporia, ao pretender promover a política do demos e rechaçar a economia política do valor (ou mérito, conforme a variante teórica e ideológica) individual, sob idênticas bases subjetivas individualistas. Sob um aspecto mais concreto - e igualmente relevante -, nota-se que, quando as lideranças formais, as organizações coletivas, os densos vínculos associativos e as subjetividades não individuais deixam a cena do protesto político, todo indivíduo torna-se um legítimo recalcitrante em relação às decisões comuns; toda pessoa 
pode negar-se a aceitar o resultado de processos deliberativos e, assim, não há como se impor deveres de solidariedade ou de engajamento em objetivos comuns (traço do neoliberalismo) e, ainda menos, como emprestar-se sentido e efetividade aos procedimentos democráticos, diante do seu caráter nada vinculante em relação ao atributo plenipotenciário de indivíduos que "não representam ninguém, senão a si”"11, em uma formulação comum nos protestos da onda global, mas nem por isso menos contraditória ou estranha às ideias de representação que a modernidade conhece, de Hobbes a Freud.

Jodi Dean identifica um realismo político na renúncia da esquerda, ao aceitar subjetividades coletivas que transcendam o individualismo neoliberal. Reconhece-se o modo de subjetividade preponderante em determinado tempo e, nos seus limites, buscam-se distinções, como a que se percebe entre cidadãs e consumidoras. Esse realismo, porém, impede a construção de formas de resistência efetivas diante da força totalizante e universalizante do capital. Ao constatar-se a impossibilidade da coletividade, a contestação social dissipa-se em uma miríade de fragmentos, frações e cizânias internas, sob a premissa de que a coletividade é, a um só tempo, indesejável (por negar as diferenças, criar espúrios conceitos de "nós" e disciplinar pessoas de modo a suprimir-lhes tanto a liberdade como a responsabilidade) e impossível (uma vez que cada pessoa é singularíssima, possui um único "lugar de fala" e, no máximo, afinidades momentâneas ou coalizões podem ser seladas) (DEAN, 2016). Aproximando-se do objeto deste artigo, Dean constata que "o realismo de esquerda é bom em indignação espontânea. Contudo, falha em organizar-se de modo que possa fazer algo com essa indignação"12 (DEAN, 2016, p. 71).

Sobre bases lacanianas, Jodi Dean avança para sustentar que a individuação preponderante no tempo presente não é narcísica, mas psicótica. O que existem são "sobreviventes", despojados da estabilização simbólica engendrada pelo "significante mestre". O argumento prossegue e conclui que, sem essa autoridade simbólica, indivíduos voltam-se ao imaginário, criando inimigos ou rivais que devem ser vencidos, ou imergindo em si, sob a conhecida lógica neoliberal de que "eu sou o meu pior inimigo". Em qualquer caso, "cada uma confronta o poder diretamente e sozinha"13 (DEAN, 2016, p. 49). Esse individualismo, que enfatiza a sobrevivente, a pessoa que luta sozinha contra um mundo hostil e injusto, conduz ao segundo atributo dos movimentos sociais contemporâneos que pode ajudar a explicar suas derrotas: a autocompaixão.

A coletividade é impossível e indesejável, de sorte que partidos, sindicatos e lideranças formais deixam a cena. As ruas são o lugar da fúria e da revolta e, ainda quando se envolvem em prefigurações, essas não costumam exceder o ensaio de sociedades estribadas em subjetividades individuais, nas quais a distribuição de tarefas, o cumprimento de programas, o respeito às decisões e o próprio engajamento encontram em cada pessoa singular um tribunal soberano, apto a aderir ou rechaçar segundo o seu alvedrio.

Um clichê do mundo neoliberal, que avança sobre os repertórios e concepções da política confrontacional transgressiva, professa que "cada pessoa que você conhece está lutando uma batalha sobre a qual você não sabe nada a respeito". Mesmo quando reunidas nas praças, as "batalhas" são únicas e não fungíveis. A boa luta, coerentemente com uma economia política que precisa justificar desigualdades e impor jornadas extenuantes sem nenhuma recompensa razoável, é aquela em que as individualidades sofrem mais, superam obstáculos maiores, submetem-se às mais inóspitas e adversas condições. Outro clichê do mundo atual - "no pain, no gain" - pavimenta a moralidade própria a sociabilidades individualizadas, constituídas por pessoas que lutam sozinhas contra adversidades monstruosas (reais ou imaginadas), além de orientar a normalização das agruras e penúrias como "oportunidades" ou "desafios" que presenteiam as melhores "guerreiras", "lutadoras". A esquerda 
política, com efeito, não é menos deslumbrada com histórias de superação individual e com o elogio do sofrimento e da humilhação, entendidos como motores de uma redenção raramente alcançada. A autocompaixão insere, na política contestatória, uma dimensão moral decomposta em dois atributos plausivelmente articulados com suas derrotas recentes: a apologia do sacrifício e a vitimização.

Como exposto acima, há um relativo consenso na literatura sobre a prevalência das práticas de ocupação dos espaços públicos em meio aos protestos da onda global. Essas ações costumam ser associadas à prefiguração de um mundo organizado horizontalmente, radical-democrático e pautado por relações humanas solidárias e colaborativas. É possível, porém, observar-se outro aspecto do mesmo fenômeno. Espaços ocupados encontram pessoas que se submetem a inúmeras privações. Falta de sono, barulho extremo, tensões no convívio, ansiedade em razão de iminentes investidas repressivas, refeições em horários irregulares, limitações quanto à higiene pessoal e instalações precárias compõem um cenário que, também em suas agruras, expõe prefigurações (CAETANO, 2016a). É frequente, contudo, a passagem da necessidade à virtude sob tais condições: o número de dias em uma ocupação, as horas sem uma refeição razoável e as reuniões realizadas sob ruído externo passam, no imaginário coletivo, a adquirir menos o predicado de problemas a serem sanados e mais de "batalhas" vencidas por "sobreviventes" que, assim, tendem a ver mérito e força precisamente nos aspectos limitadores e enfraquecedores dos repertórios adotados. Da mesma sorte, a relação com a coerção penal e com o uso de violência física pelo Estado tende a ser menos objeto de reavaliação crítica dos eventuais erros ou desacertos organizacionais (que culminam em consequências como prisões), para cederem terreno à glorificação dos detidos. Como escreve Caetano (2016b), jovem doutorando em Ciência Política e ativista, que esteve na prisão no contexto dos eventos de protestos ocorridos no Brasil entre 2013 e 2014, no tempo da autocompaixão, falta "entender que glorificar a derrota (e prisões nada mais são que isso, derrotas) não ajudará a esquerda em nada” (CAETANO, 2016b).

Dessa apologia do sacrifício ressai uma moralidade paralisante: a vitimização. Em um mundo de "sobreviventes", em que toda a injustiça leva-nos a provas e provações redentoras, o poder (ainda que no sentido de capacidade ou força, antes de violência ou dominação) é suspeito. A política contestatória legitima-se não apenas na individualidade, mas naquela que sofre, que o faz intensa e solitariamente, de modo que ninguém, senão a singularíssima unidade individual situada em seu lugar de fala, é capaz de entender ou representar. Sair da condição de sofrimento e de dominação, com efeito, implica deixar o terreno da moralidade; ou seja, perder a legitimidade para o engajamento na ação contestatória. Emerge, portanto, um curto-circuito: o lugar da validade moral e da legitimidade política está na posição de sofrimento, de modo que não se pode deixá-la, sob pena de perderem-se as condições para agir de maneira moral e política. A vitória, portanto, não é um norte das lutas que, assim, sempre correm o risco de ficar mais próximas de cacofônicas performances catárticas, levadas à praça por somas de individualidades vitimadas, cada qual a seu modo, do que de ações coletivas orientadas à subjugação de adversários ou inimigos comuns. Como afirma Dean (2009), a apologia da condição de vítima leva à aporia em que "para falar qualquer coisa, elas [ativistas] devem demonstrar como são injuriadas e vulneráveis, como são fracas, inadequadas ou sofridas” (DEAN, 2009, p. 5). O desdobramento desse cenário é que nunca se deixa essa condição, pois, prossegue a autora, "para muitas esquerdistas, a atração da posição de vítima é, assim, dupla: está-se sempre moralmente correta - pois quem pode negar o sofrimento da vítima? - e nunca se é politicamente responsável - pois as vítimas são muito fracas e feridas para governarem" (DEAN, 2009, p. 6) ${ }^{14}$. De fato, a julgar-se pelo modo como o ativismo do século XXI entende-se como projeção tardia de ciclos de confronto político como Maio de 1968 e renega processos como a Revolução Bolchevique, é pertinente desenvolver-se a hipótese de que as 
derrotas são, antes de um desvio de curso, a condição de moralidade própria a subjetividades ativistas que parecem seguir mais os passos de Savonarola do que de Maquiavel.

Ressai dessa leitura, sobre a Onda Global de Protestos como marcada pelo individualismo neoliberal e pela autocompaixão, a partir da crítica marxista-lacaniana de Jodi Dean, que o momento de perecimento global das democracias e dos direitos humanos pode somar o elemento dos limites e das contradições internas às lutas contestatórias ao rol de explicações lançadas para a respectiva compreensão.

\section{Considerações Finais}

Este artigo pretendeu desenvolver, por meio de uma exposição ensaística, a plausibilidade teórica do argumento de que o momento histórico atual - em que a lógica econômica neoliberal avança globalmente, sob governos crescentemente alheios ao princípio democrático - pode associar-se aos limites do ativismo contemporâneo. As subjetividades e a moralidade prevalentes durante a Onda Global de Protestos são uma faceta pouco perquirida, mas promissora, para o entendimento das novíssimas obscuridades do mundo contemporâneo.

Primeiramente, justificou-se a premissa de que esses ciclos de protestos distinguem-se do Movimento de Justiça Global. Não se tratou de um movimento articulado globalmente, com a finalidade de enfrentar-se adversários transnacionais, como se dera nas lutas dos anos 1990 e início dos anos 2000 (quando a luta por um "outro mundo possível" operava sobre alvos como o G-8, a OMC, o FMI e o Fórum Econômico Mundial). Na Onda Global de Protestos, questões locais, sempre associadas aos Estados nacionais e às vicissitudes dos processos sociais e políticos de cada país, articularam-se e influenciaram-se, de modo e emergir uma onda, diferentemente de um movimento. As peculiaridades locais dos ciclos de protestos, contudo, não os certificam apenas como coleções de casos isolados, uma vez que a circulação de ativistas, as mútuas referências, os repertórios comuns e um pano de fundo associado à insurgência em favor de mais democracia e de menos políticas de retração fiscal indicam a conexão entre o que se passou em diferentes localidades.

Constatado o leitmotif da luta por democracia (seja por sua conquista em situações autocráticas, como a do Egito, seja por sua radicalização, como na Espanha) e contra práticas fiscais contracionistas (observadas desde as políticas europeias de austeridade à abstenção do Estado brasileiro em custear o direito ao transporte), justificou-se o argumento de que, sob esse aspecto, a Onda Global de Protestos, em que pese o seu perene e positivo legado em incontáveis dimensões políticas e culturais, já documentadas pela literatura, restou malograda.

Procedeu-se, enfim, à contribuição proposta neste artigo. A partir da linha teórica que entende o estudo de movimentos sociais como susceptível à abordagem, a partir de uma perspectiva intrínseca ao ativismo e capaz de tomar os seus rumos como variáveis independentes na produção dos resultados experimentados, buscou-se identificar dois atributos disseminados nas ruas da Onda Global de Protestos, cujo efeito sobre o respectivo malogro entendeu-se como plausível: i) o individualismo neoliberal ${ }^{15}$ como subjetividade prevalecente; e ii) a autocompaixão como moralidade recorrente.

A partir da filosofia política de Jodi Dean, sustentou-se que as lutas sociais, quando encapsuladas em subjetividades individuais e atreladas a uma moralidade apologética em relação à privação, à martirização e à vitimização, têm poucas chances de vencer seus adversários e, assim, construir a realidade pela qual se propõe a lutar. Em um sentido lordiano, conclui-se com a constatação 
de que o individualismo neoliberal e a moralização do sofrimento são as armas do senhor que, com efeito, não se revelam aptas a destruír o respectivo castelo (LORDE, 2015).

Espera-se, com este ensaio, contribuir para o estímulo a ulteriores aportes empíricos sobre a dimensão político-confrontacional do retrocesso experimentado globalmente pela democracia e pelos direitos humanos; sobre o modo como os elementos da individualização e da autocompaixão manifestam-se em diferentes ciclos de confronto político: e sobre novas subjetividades coletivas, que contrastam ou infirmam as tendências aqui apresentadas. Ambiciona-se, igualmente, a instigação de mais estudos teóricos orientados a elementos que exorbitam sobre mecanismos e processos em eventos de protestos, em favor de construções que, crítica e solidariamente, contribuam para que a compreensão das derrotas do presente projete as vitórias do porvir.

\section{Contribuições dos Autores}

Problematização e conceitualização: Tavares FMM; Metodologia: Tavares FMM, Pfrimer MH; Análise: Tavares FMM; Redação: Tavares FMM, Pfrimer MH.

\section{Notas}

1. Como afirmam os autores: "Now, to return to McAdam, Tarrow, and Tilly, they never seem to provide a basis for saying, 'They blew it....' (or, of course, 'They got it right, for the following reasons')” (COX, 2002, p. 3). O propósito deste artigo reside, precisamente, em inventariar problemas nas escolhas, nos cursos de ação e nas subjetividades que informam a onda global de protestos, sugerindo a sua provável influência sobre os malogros ulteriores quanto aos propósitos de radicalização democrática e promoção de direitos sociais.

2. Para citarem-se três exemplos, Ziblatt (2018) centram-se na inoperância dos partidos como "porteiros" das democracias contra líderes autocráticos; Offe (2013) ocupa-se de um problema situado na "oferta" de políticas, a frustrar o eleitorado, diante da crise fiscal; e Fukuyama (2015), observa um problema no plano das capacidades estatais.

3. A tese do "fim da história" como resultante do ocaso das burocracias soviéticas é, recorrentemente, associada ao pensamento neo-hegeliano de Fukuyama. O teórico político, de fato, indagou sobre tal possibilidade em um artigo lançado em 1989 e a afirmou em um livro publicado já em 1992 (FUKUYAMA, 1989; 1992). Não se trata, contudo, do único a eternizar os atributos do tempo então emergente. No campo crítico, por exemplo, Jürgen Habermas, em um artigo publicado no ano de 1991, a propósito da queda da União Soviética, apresentava um novo significado para a ideia de socialismo, ancorado na tese de que a esquerda teria "de transformar as ideias socialistas em autocrítica radicalmente reformista de uma sociedade capitalista que, juntamente com suas fraquezas, desenvolveu suas forças nas formas de uma democracia de massas do Estado social e democrático de direito" e de que "sociedades complexas não podem se reproduzir se não deixam intacta a lógica de auto-orientação de uma economia regulada pelos mercados" (HABERMAS, 1991, p. 56).

4. Tradução livre. No original: "If Greece is the future of Europe, perhaps in another sense resistance might become Europe's future too."

5. Um caso que costuma ser mencionado como exceção é, precisamente, o dos protestos brasileiros em 2013. O argumento é que, à época, o governo aumentava gastos sociais e a democracia no país parecia suficientemente consolidada e prestigiada. Quanto à primeira observação, trata-se de uma leitura não atenta às peculiaridades do federalismo do Brasil. No país, os protestos de 2013 iniciaram-se, em favor de políticas sob competência constitucional dos municípios 
(como transporte coletivo público urbano), que, por sua vez, encontravam-se sob restrições fiscais e impunham medidas antissociais de jaez neoliberal, como autorização para o aumento de tarifas (TAVARES; BENEDITO, 2018; BIRCHAL, 2019). Já em relação ao segundo aspecto, basta constatar que a mais notória reação presidencial aos protestos consistiu em um anúncio de um plebiscito (forma participativa por si só) orientado à realização de uma reforma político-eleitoral (que, aliás, jamais ultimou-se).

6. Tradução livre. No original: "feeling of antipolitics may indeed threaten the quality of democracy."

7. Tradução livre. No original: "repensarlos a partir de otros parámetros, ampliando, por ejemplo, nuestras investigaciones."

8. Tradução livre. No original: "no implica simplemente idealizar a los movimientos, sino estar dispuesto a activar la escucha y el diálogo crítico.”

9. Tradução livre. No original: “...a longing for horizontality, the negation of representation and the rejection of formal leadership.".

10. Tradução livre. No original: "Collective action as well underwent change: There is a greater protagonism of individuals and public squares.".

11. No mesmo sentido: "Exactly how politics involves the individual varies - no speaks for me but me; the personal is political; if I can't dance I don't want to be part of your revolution. But the premise remains the same: a left politics has to encourage and express the multiplicity of individual projects. Individuals have to choose and decide - even as the left fails to provide something anyone could actually choose. Leaders, vanguards, and parties are modes of politics for a time not our own, we are told" (DEAN, 2016, p. 71).

12. Tradução livre. No original: "Left realism is good on spontaneous outrage. But it fails to organize itself in a way that can do something with this outrage..”

13. Tradução livre. No original: "each confronts power directly and alone".

14. Tradução livre. No original: "to speak at all they have to demonstrate how they are harmed and vulnerable, how they are weak, inadequate, or suffering.[...] For many leftists, the attraction of the postition of victim is thus double: one is always morally correct - for who can deny the suffering of the victim? - and never politically responsible - for victims are too weak and injured to govern.”.

15. Predica-se individualismo como "neoliberal", na esteira da noção de individualidades "sobreviventes" proposta por Dean (2016), que estariam a viver em uma épica "batalha” solipsista para conseguirem obter um mínimo de dignidade, sem contarem com a solidariedade ou cumplicidade coletivas, como da redução do humano à firma individual, regida e codificada em termos estritamente econômicos, na forma como Windy Brown resgata o pensamento foucaultiano (BROWN, 2015). Para uma concepção de indivíduo que pressuponha vínculos dialeticamente constitutivos com a sociedade e não incorra nas aporias aqui assinaladas a essa forma de subjetividade, confira-se SAYERS,(2007).

\section{Referências}

ARRAIS, T. A; VIANA, J. L. Pequeno atlas da tragédia previdenciária brasileira. Goiania: UFG, 2019. BADIOU, A. The rebirth of history: Times of riots and uprisings. London: Verso, 2012.

BARKER, C.; COX, L. "What have the romans ever done for us?" Academic and activist forms of movement theorizing. Proceedings of the Eighth International Conference on Alternative Futures and Popular Protest. Manchester Metropolitan University, Apr. 2002. Disponível em: <http://mural. maynoothuniversity.ie/428/1/AFPPVIII.pdf>. Acesso em: 24 ago. 2019. 
BERGMAN, E. Nordic nationalism and right-wing populist politics. Imperial relationships and national sentiments. London: Palgrave Macmillan, 2015.

BIRCHAL, L. D. Junho de 2013: Atores, práticas e gramáticas nos protestos em Belo Horizonte. 2019. Dissertação (Mestrado em Ciência Política) - Departamento de Ciência Política, Universidade Federal de Minas Gerais,. Belo Horizonte, 2019.

BRINGEL, B. Social movements and contemporary modernity: Internationalism and patterns of global constestation. In: BRINGEL, B; DOMINGUES, J. M. (eds). Global modernity and social contestation. Londres: Sage, 2015. http://doi.org/10.4135/9781473916449.n8

BRINGEL, B.; PLEYERS, G. Introducción: Movimentos sociales em el mundo contemporáneo. In: BRINGEL, Protesta e indignación global: Los movimentos sociales em el nuevo orden mundial. Buenos Aires: CLACSO/Rio de Janeiro: FAPERJ , 2017.

BROWN, W. Undoing the Demos: Neoliberalism's stealth revolution. New York: Zone Books, 2015.

CAETANO, I. Miopia objetiva e os dilemas do mártir: O ethos ativista vis-à-vis as prisões de aderentes de protesto. Passapalavra, out. 2016a. Disponível em: <https://passapalavra.info/2016/10/109496/>. Acesso em: 6 ago. 2019.

CAETANO, I. Oh, love, you' re not alone: Sobre as ocupações, o "novo" e suas decorrências, Passapalavra, nov. 2016b. Disponível em: <http://passapalavra.info/2016/11/109907>. Acesso em: 6 ago. 2017.

CHITTY, A. Recognition and social relations of production. Historical Materialism, n. 2, p. 57-97, summer 1998. doi: https://doi.org/10.1057/9780230595934_8

DE LA PEÑA, E. El gasto social del PP o el juego de la trila. CTXT - Revista Contexto, abr. 2018. Disponível em: <https://ctxt.es/es/20180404/Politica/18818/presupuestos-2018-montoro-gastopublico-pensiones-sanidad-emilio-de-la-pe\%C3\%B1a.htm>. Acesso em: 10 ago. 2019.

DEAN, J. Democracy and other neoliberal fantasies: Communicative capitalism and left politics. Durham: Duke University Press, 2009.

DEAN, J. Crowds and party. Londres: Verso, 2016.

DELLA PORTA, D. Social movements in times of austerity. Cambridge: Polity Press, 2015.

DOUZINAS, C. Philosophy and resistance in the crisis: Greece and the future of europe. Cambridge: Polity Press, 2013.

ELIAS, N. O processo civilizador. Volume 2: Formação do Estado e Civilização. Trad. Ruy Jungmann. Rio de Janeiro: Zahar, 2011.

FERNANDEZ-SAVÁTER, A.; FOMINAYA, C. F.; CARVALHO, L. Life after the squares: Reflections on the consequences of the occupy movements. Social Movements Studies, v. 16, n. 1, p. 119-151, 2017. https://doi.org/10.1080/14742837.2016.1244478

FOMINAYA, C. F. Social movements and globalization: How protests, ocuupations and uprisings are changing the world. Nova York: Palgrave Macmillan, 2014. 
FUKUYAMA, F. The end of history? The National Interest, summer 1989. Disponível em: <http:// www.wesjones.com/eoh.htm>. Acesso em: 26 maio. 2019.

FUKUYAMA, F.The end of history and the last man. Nova York: Free Press, 1992.

FUKUYAMA, F. Why is democracy performing so poorly? Journal of Democracy, v. 26, n. 1, jan. 2015. Disponível em: <https://fsi.stanford.edu/sites/default/files/ff_jod_jan2015.pdf >. Acesso em: 10 jul. 2017.

HABERMAS, J. Que significa socialismo hoje? Revolução recuperadora e necessidade de revisão da esquerda. Trad. Márcio Suzuki. Novos Estudos, São Paulo, n. 30, jul. 1991. p. 43-60.

HUSSAIN, M. M; HOWARD, P. N. Democracy's fourth wave? Information technologies and the fuzzy causes of the Arab Spring, Mar. 2016. http://doi.org/10.2139/ssrn.2029711.

LEVISTKY, D.; ZIBLATT, S. How Democracies Die. Nova York: Vinking, 2018.

LORDE, A. The master tools will never dismantle the master's house, 2015. Disponível em: <http:// www.historyisaweapon.com/defcon1/lordedismantle.html>. Acesso em: 20 jul. 2019.

MINC, A. Le nouveau Moyen Age. Paris: Galimard, 1993.

MONEDERO, J. C. La transición contada a nuestros padres. Madrid: Catarata, 2013.

NORRIS, P.; INGLEHARDT, R. Cultural backlash: Trump, Brexit and authoritarian populism. Cambridge: Cambridge University Press, 2019.

O'BRIEN, T. Populism, protest and democracy in the twenty-first century. Contemporary Social Science, v. 10, n. 4, 2015. https://doi.org/10.1080/21582041.2016.1237438

OFFE, C. Participatory inequality in the austerity state: A supply-side approach. In: SCHÄFER, A.; STREECK, W. (eds). Politics in the Age of Austerity. Cambridge: Polity, 2013. https://doi. org/10.1007/978-3-658-22265-9_11

SAYERS, S. Individual and society in Marx and Hegel: Beyond the communitarian critique of liberalism. Science and Society, v. 71, n. 1, jan. 2007.

SMITH, H. L. Erdogan gives Turkish military immunity. The Times. 15 june 2016. Disponível em: $<$ https://www.thetimes.co.uk/article/turkish-military-given-immunity-as-erdogan-seeks-allies3fcpwc2jk>. Acesso em: 11 ago. 2019.

STREECK, W. Buying time: The delayed crisis of democratic capitalism. Londres: VERSO, 2014.

TAVARES, F. M. M.; BENEDITO, S. M. Pós-democracia no Sul Global: Uma leitura sócio-fiscal dos confrontos políticos e da ruptura institucional no crepúsculo da nova república brasileira (2003-2017). Revista Sul-Americana de Ciência Política, v. 4, n. 2, p. 179-196, dez. 2018.

TRANSPARENCY INTERNATIONAL. Corruption Perception Index 2018. Disponível em: <https:// www.transparency.org/cpi2018>. Acesso em: 12 ago. 2019.

TÜRKMEN, B. Del Parque Gezi a la transformación del paisaje político de Turquía. In: BRINGEL, B.; PLEYERS, G. Protesta e indignación global: Los movimientos sociales en el nuevo orden mundial. Buenos Aires: CLACSO/Río de Janeiro: FAPERJ, 2017, p. 53-60. 
UCDP [UPPSAla CONFLICT DATABASE PROJECT]. Definitions. 2015. Disponível em: <https:// www.pcr.uu.se/research/ucdp/definitions/>. Acesso em: 11 ago. 2018

WOOD, E. Liberty and property: A social history of Western political thought from the Renaissance to Enlightenment. Londres: Verso, 2012.

ZIZEK, S. The year of dreaming dangerously. Londres: Verso, 2012.

\section{Sobre os Autores}

Francisco Mata Machado Tavares é bacharel em direito, mestre e doutor em ciência política pela Universidade Federal de Minas Gerais. É professor na Universidade Federal de Goiás, onde atua nos programas de pós-graduação em direitos humanos e em ciência política, além de coordenar o Grupo de Estudos e Pesquisas Sócio-Fiscais (GESF).

Matheus Hoffmann Pfrimer é mestre em Relações Internacionais pela Universidade de Liège e doutor em Geografia pela Universidade de São Paulo É professor na Universidade Federal de Goiás, onde atua no programa de pós-graduação em ciência política.

Recebido: 23 Nov 2019

Aceito: 27 Jan 2020 